\title{
The Effects of Aerobic-Resistance Training and Broccoli Supplementation on Plasma Dectin-1 and Insulin Resistance in Males with Type 2 Diabetes
}

\author{
Ayoub Saeidi ${ }^{1}$ D, Mohammad Soltani ${ }^{2}$, Ali Daraei ${ }^{3}$, Hanieh Nohbaradar ${ }^{4}$, Marjan Mosalman Haghighi ${ }^{5}$, \\ Nikoo Khosravi ${ }^{4}$, Kelly E. Johnson ${ }^{6}$, Ismail Laher ${ }^{7}$ D, Anthony C. Hackney ${ }^{8}$, Trisha A. VanDusseldorp ${ }^{9, *(D)}$ and \\ Hassane Zouhal 10,*iD
}

check for updates

Citation: Saeidi, A.; Soltani, M.; Daraei, A.; Nohbaradar, H.; Haghighi, M.M.; Khosravi, N.; Johnson, K.E.;

Laher, I.; Hackney, A.C.;

VanDusseldorp, T.A.; et al. The Effects of Aerobic-Resistance Training and Broccoli Supplementation on Plasma Dectin-1 and Insulin Resistance in Males with Type 2 Diabetes. Nutrients 2021, 13, 3144 https://doi.org/10.3390/nu13093144

Received: 12 August 2021

Accepted: 7 September 2021

Published: 9 September 2021

Publisher's Note: MDPI stays neutral with regard to jurisdictional claims in published maps and institutional affiliations.

Copyright: () 2021 by the authors Licensee MDPI, Basel, Switzerland. This article is an open access article distributed under the terms and conditions of the Creative Commons Attribution (CC BY) license (https:/ / creativecommons.org/licenses/by/ $4.0 /)$
1 Department of Physical Education and Sport Sciences, University of Kurdistan, Sanandaj 66177-15175, Iran; saeidi_as68@yahoo.com

2 Department of Biological Sciences in Sport, Faculty of Sports Sciences and Health, Shahid Beheshti University, Tehran 19839-69411, Iran; m.soltani904@gmail.com

3 School of Health \& Exercise Sciences, The University of British Columbia, Kelowna, BC V1V 1V7, Canada; alidaraei01994@gmail.com

4 Faculty of Sports and Exercise Sciences, Alzahra University, Tehran 19938-93973, Iran; haniye70_sa@yahoo.com (H.N.); nikukh@alzahra.ac.ir (N.K.)

5 Faculty of Medicine and Health, The University of Sydney, Sydney 2006, Australia; marjan.mosalmanhaghighi@sydney.edu.au

6 Department Kinesiology, Coastal Carolina University, Conway, SC 29526, USA; kjohns10@coastal.edu

7 Department of Anesthesiology, Pharmacology \& Therapeutics, The University of British Columbia, Vancouver, BC BV6T 1Z3, Canada; ismail.laher@ubc.ca

8 Department of Exercise \& Sport Science and Department of Nutrition, University of North Carolina, Chapel Hill, NC 27599, USA; ach@email.unc.edu

9 Department of Exercise Science and Sport Management, Kennesaw State University, Kennesaw, GA 30144, USA

10 M2S (Laboratoire Mouvement, Sport, Santé)-EA 1274, University of Rennes, F-35000 Rennes, France

* Correspondence: tvanduss@kennesaw.edu (T.A.V.); hassane.zouhal@univ-rennes2.fr (H.Z.)

\begin{abstract}
Background: This study aimed to evaluate the effects of a combination of aerobic-resistance training (CARET) and broccoli supplementation on dectin-1 levels and insulin resistance in men with type 2 diabetes mellitus (T2D). Methods: Forty-four males with T2D were randomly allocated to four groups ( $n=11$ each group): CARET + broccoli supplement (TS), CARET + placebo (TP), control + broccoli supplement (S), and control + placebo (CP). CARET was performed three days per week for 12 weeks. TS and S groups received $10 \mathrm{~g}$ of broccoli supplement per day for 12 weeks. All variables were assessed at baseline and 12 weeks. Results: Plasma dectin-1 levels were decreased in TS and TP groups compared with the CP group $(p<0.05)$. Cardiometabolic risk factors showed significant reductions in TP and TS groups compared to $S$ and $C P$ groups $(p<0.05)$. Conclusion: The combination of CARET and broccoli supplementation produced the largest improvements in insulin resistance and dectin- 1 and other complications of T2D.
\end{abstract}

Keywords: aerobic-strength training; concurrent exercise training; HOMA-IR; inflammation; body mass index; fat percent; broccoli

\section{Introduction}

Type 2 diabetes mellitus (T2D) is a global epidemic with high morbidity and mortality rates [1]. Risk factors such as obesity, unhealthy eating habits, and a sedentary lifestyle increase the risk of T2D [2,3]. Both obesity and T2D are associated with increased oxidative stress and inflammatory markers, which also have detrimental effects on the immune system [4].

Dectin-1 is a member of the C-type lectin receptor family that is highly expressed in macrophages and dendritic cells [5]. Dectin-1 is an innate immune receptor involved in 
various cellular responses, including in chronic inflammatory conditions such as autoimmunity and T2D [5,6]. Activation of dectin- 1 induces the production of pro-inflammatory cytokines, chemokine [6], and reactive oxygen species [7], and dectin-1 is suggested to play a role in obesity-associated inflammation and insulin resistance, making it a therapeutic target in the treatment of chronic inflammation in insulin-resistant individuals [8].

Broccoli and broccoli sprouts are rich sources of bioactive compounds such as isothiocyanates, antioxidant vitamins, and selenium [9]. A key component of broccoli is sulforaphane, which reduces lipid peroxidation, increases total antioxidant capacity, and decreases oxidative stress by activating antioxidant pathways in T2D patients [10]. It has been reported that four weeks of supplementation with broccoli $(10 \mathrm{~g} / \mathrm{d})$ decreases serum insulin concentrations and homeostatic model assessment of insulin resistance (HOMA-IR) in individuals with T2D [11]. Furthermore, sulforaphane (i.e., sulfur-rich compound found in cruciferous vegetables such as broccoli) inactivates NF-kB (nuclear factor kappa-light-chain-enhancer of activated B cells) inhibition of cytokine production, suggesting a possible beneficial effect in TD2 [11,12]. Administering sulforaphane increases muscle strength, improves muscle function and exercise capacity, and protects muscle from oxidative damage and inflammation [13]. Moreover, sulforaphane activates nuclear factor erythroid 2-related factor 2 (Nrf2) and reduces exercise-induced muscle fatigue by upregulating cellular antioxidant mechanisms and phase 2 enzymes involved in conjugation reactions [14]. Sulforaphane also decreases markers of muscle damage, such as creatinine phosphokinase and lactate dehydrogenase [15]. Although exercise can increase pro-inflammatory cytokines in the liver, kidney, and intestine [16,17], sulforaphane induces phase 2 enzymes through Nrf2 activation to reduce oxidative insults [16]. In addition, dietary supplementation with broccoli extract reduces exercise-induced muscle soreness and oxidative stress markers in T2D patients [18].

It is well known that changes in lifestyle such as a healthy diet and increased physical activity can attenuate the complications of T2D [19]. Combined exercise training aerobic + resistance (CARET) has recently been recommended for managing T2D; CARET may be more effective than either aerobic or resistance training alone in improving insulin resistance, inflammatory markers, glucose transporter type 4 (GLUT-4) expression (by increasing muscle mass), body weight, visceral fat mass, and lipid profiles in individuals with obesity and T2D $[19,20]$. In addition, CARET improves immune function by converting M1 macrophages to M2 subtypes, so reducing inflammation in obesity and T2D [21,22]. Although exercise training is often performed on most days of the week, CARET could have deleterious effects on inflammatory factors, endothelial function, and hemodynamic balance in sedentary individuals with obesity and T2D [22,23]. Therefore, CARET, which engages more groups of exercising muscles and requires greater energy expenditure, can increase pro-inflammatory factors, especially in the first month of the intensive exercise training program [24]. These findings emphasize the importance of tailoring optimal guidelines of aerobic and resistance training plus an ergogenic aid in individuals with T2D, especially in a population of sedentary individuals with obesity and T2D, whose pro-inflammatory factors are higher than their counterparts who have a healthy lifestyle [24].

Both CARET and broccoli supplementation separately improve obesity, diabetes, and inflammatory markers [11,22], although the effects of a combination of the two on plasma dectin-1, cardiometabolic risk factors, and body composition variables are unknown. Therefore, we hypothesized that 12 weeks of combined CARET and broccoli supplementation would have greater effects on cardiometabolic variables in individuals with T2D than the benefits from using either exercise training or broccoli supplement in isolation.

\section{Materials and Methods}

\subsection{Participants}

Forty-four men (see Table 1 for participant characteristics) clinically diagnosed with T2D participated in this study. They were recruited from local hospitals and health centers 
through advertisements (i.e., poster/flyer, email, and social media applications). A sports medicine physician and an endocrinologist screened all participants to ensure they were healthy enough to participate in the study. Inclusion criteria included: patients with T2D as defined by the American Diabetes Association, the age range of 40 to 60 years, duration of diabetes $>2$ years, fasting plasma glucose concentration of $7.0 \mathrm{mmol} / \mathrm{L}$ or higher (i.e., $126 \mathrm{mg} / \mathrm{dL}$ or higher), and being treated with an oral hypoglycemic medication. Subjects were excluded if they had: hypertension $(>160 / 90 \mathrm{mmHg})$ or other cardiovascular diseases, musculoskeletal disorders, respiratory diseases, neurological disorders, renal dysfunction, or other disorders that could limit physical activity (Figure 1). A written consent form was obtained from all subjects before the study. All subjects participated in a familiarization session where they were acquainted with the study procedures, benefits, and potential risks. All study procedures and protocols were approved by the local University Research and Ethics Committee (Ethics code: IR-IAU1397-3) and performed according to the latest revision of the Declaration of Helsinki [25].

Table 1. CARET (Combine Aerobic + resistance Exercise Training) for 12 weeks.

\begin{tabular}{|c|c|c|c|c|c|c|c|}
\hline \multirow[b]{2}{*}{ Weeks } & \multicolumn{3}{|c|}{ Aerobic Training } & \multicolumn{4}{|c|}{ Resistance Training } \\
\hline & $\begin{array}{c}\text { Duration } \\
\text { (min/Sessions) }\end{array}$ & $\begin{array}{l}\text { Intensity } \\
\left(\mathrm{VO}_{2 \text { peak }}\right)\end{array}$ & $\begin{array}{l}\text { Sessions Per } \\
\text { Week }\end{array}$ & Sets & Repetitions & 1-RM & $\begin{array}{c}\text { Sessions Per } \\
\text { Week }\end{array}$ \\
\hline 1 to 2 & 10 & $60 \%$ & 3 & 3 & $12-15$ & $60-65 \%$ & 3 \\
\hline 2 to 4 & 15 & $65 \%$ & 3 & 3 & $12-15$ & $60-65 \%$ & 3 \\
\hline 4 to 6 & 20 & $70 \%$ & 3 & 3 & $8-10$ & $70 \%$ & 3 \\
\hline 6 to 8 & 25 & $70 \%$ & 3 & 3 & $8-10$ & $70 \%$ & 3 \\
\hline 8 to 12 & 30 & $70 \%$ & 3 & 3 & $8-10$ & $70 \%$ & 3 \\
\hline
\end{tabular}

1-RM, one-repetition maximum.

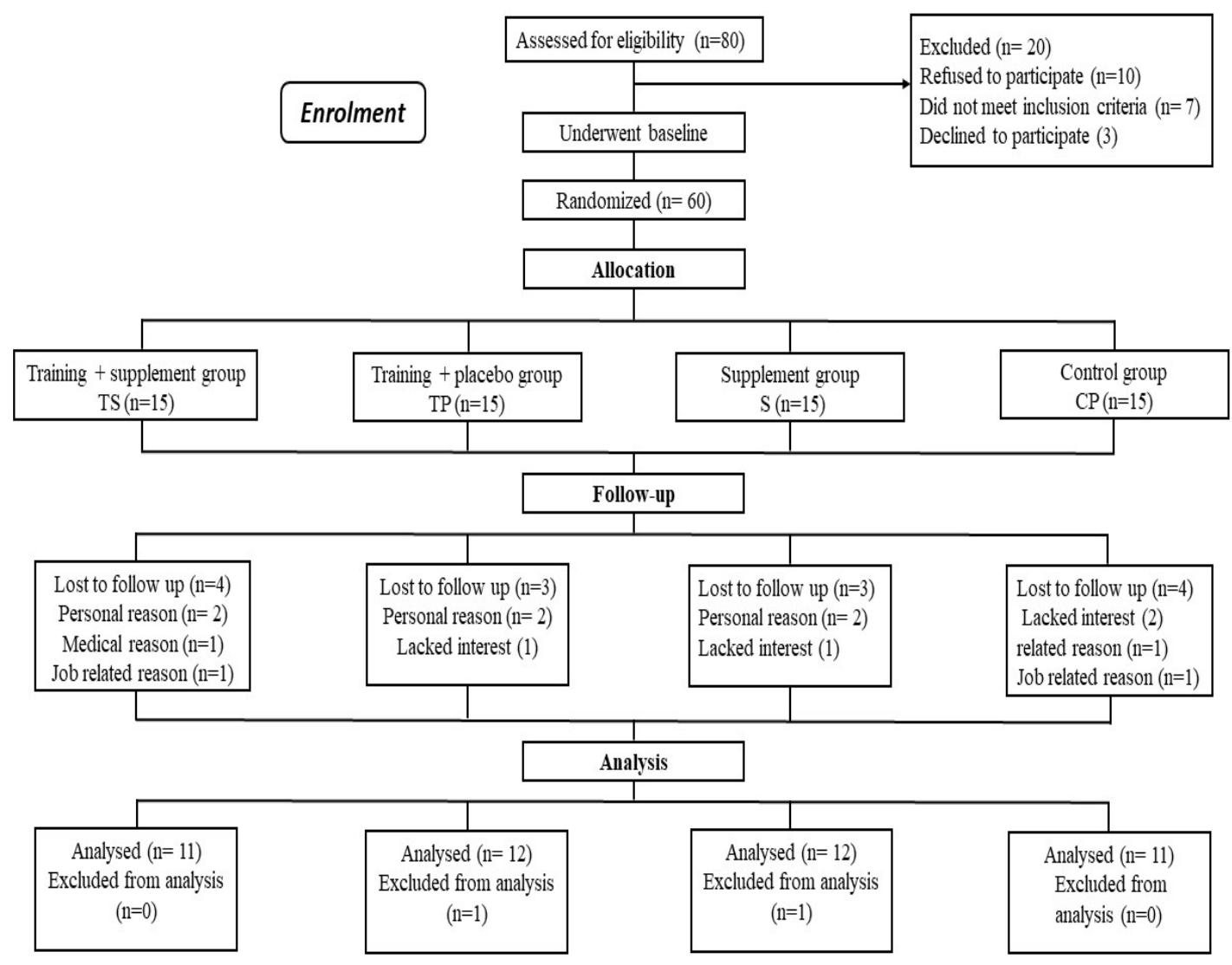

Figure 1. Participants flow chart. CP, Control-Placebo; S, Supplement; TP, Training-Placebo; TS, Training-Supplement. 


\subsection{Experimental Design}

Subjects were randomly assigned to four study groups ( $n=11$ per group): training + broccoli supplement (TS), training + placebo (TP), control + broccoli supplement (S), and control + placebo (CP) (Figures 1 and 2). The randomization was conducted using a random number table. An independent coordinator (a dietitian) who was not involved in the study assigned participants to the TS, TP, S, and CP groups, and all participants were instructed to continue with their current medications and maintain their diets. Participants in the control group were instructed to maintain their current lifestyles until the end of the study. All participants were asked to fast for $12 \mathrm{~h}$, avoid strenuous exercise for two days, and remain well hydrated prior to blood draws that were taken $48 \mathrm{~h}$ before the start of the program and $48 \mathrm{~h}$ after the 12-week exercise training program. Height and body mass were measured to determine BMI (weight $(\mathrm{kg})$ divided by height ${ }^{2}\left(\right.$ meters $\left.^{2}\right)$ ) before and after the study. Three familiarization sessions that included a 5- to 10-min warm-up, $20 \mathrm{~min}$ of resistance exercise, followed by performing $20 \mathrm{~min}$ of aerobic exercise at a moderate intensity, were held before starting the study.

Pre-test: $-\mathbf{7 2} \mathrm{h}$
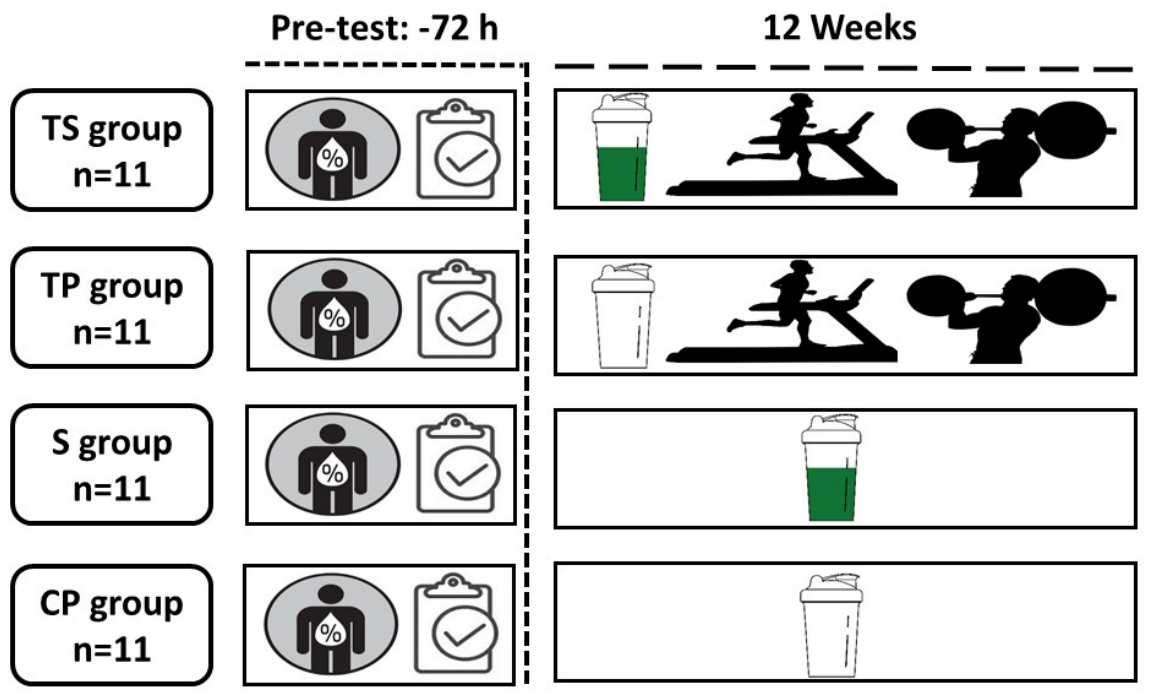

Post-test: $\mathbf{+ 7 2} \mathrm{h}$
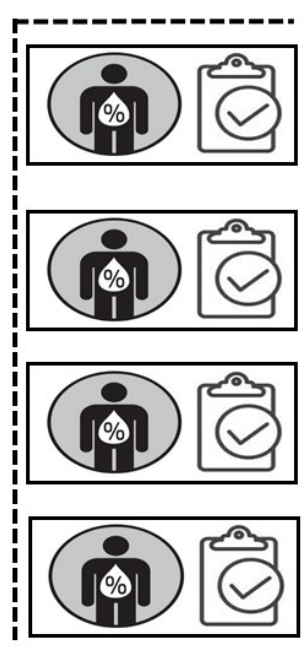

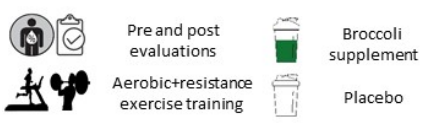

Figure 2. Experimental design. CP, Control-Placebo; S, Supplement; TP, Training-Placebo; TS, Training-Supplement.

\subsection{Cardio-Respiratory Fitness, Body Composition and One-Repetition Maximum Assessments}

A modified Bruce protocol using a motorized treadmill (Pulsar 3p, H/P/Cosmos, Nussdorf-Traunstein, Germany) with a gas analyzer system (Metalyzer 3B Analyzer, Cortex Biophysik, Leipzig, Germany) was used to estimate peak oxygen uptake $\left(\mathrm{VO}_{2 \text { peak }}\right)$ in a temperature-controlled room $\left(21-23^{\circ} \mathrm{C}\right)$. Blood pressure was recorded during the test using an automated blood pressure system (Omron M6 Comfort, HEM-7221-E, Omron Healthcare, Kyoto, Japan) and heart rates (HR) (beats/minute) were continuously recorded using an HR monitor (Polar Electro, Espoo, Finland). Participants reported their perceived exertion rating using the Borg scale (6-20) during the last $10 \mathrm{~s}$ of each phase of the test [26]. $\mathrm{VO}_{2 \text { peak }}$ was determined by using the following criteria (According to American College of Sports Medicine guidelines for CPET test): (A) exhaustion based on a Borg scale of $>17$, (B) if the supervising physician observed or if the subjects reported dyspnea, dizziness or any contra indicatory symptoms, $(\mathrm{C})$ a plateau in $\mathrm{VO}_{2}$ and (D) respiratory exchange ratio (RER) $\geq 1.10$. Body fat percentage (\%) and fat free mass (FFM) were measured by a bio-impedance analyzer (Medigate Company Inc., Dan-dong Gunpo, Korea) before and after the exercise training program. One-repetition maximum (1-RM) was determined 
during the last familiarization session. After a five minute warm-up, participants lifted the maximal amount of weight that could be lifted for 6-8 repetitions for each exercise (described below), and then 1 RM was calculated according to the Brzycki formula [27]. Participant rested for two minutes between exercise and attempts.

\subsection{Exercise Training Program}

A specialist in sports medicine and a clinical exercise physiologist supervised all training sessions. The training groups performed exercises three times a week for 12 weeks. The training program volume and intensity were designed using prescribed exercise guidelines for patients with T2D [28]. Each training session included a 5- to 10-min warm-up, $45 \mathrm{~min}$ of resistance training at $60-70 \%$ of 1-RM which was then followed by $30 \mathrm{~min}$ of aerobic exercise at $60-70 \%$ of $\mathrm{VO}_{2 \text { peak }}$ on a motorized treadmill (Pulsar $3 p$, $\mathrm{H} / \mathrm{P} /$ Cosmos, Nussdorf-Traunstein, Germany). Resistance exercise consisted of eight exercises: upper and lower body (leg press, knee flexion, knee extension, chest press, lat pull-down, shoulder press, abdominal crunches, biceps curls, triceps press down). In order to meet the overloading principle, the 1-RM and $\mathrm{VO}_{2 \text { peak }}$ test were repeated every four weeks. The aerobic exercise time was 10 min during the initial weeks and was gradually increased to $30 \mathrm{~min}$ by the eighth week, which continued until the end of the study. The details of both the aerobic and resistance exercise training are presented in Table 1.

\subsection{Nutrient Intake and Dietary Analysis}

Participants were instructed to document their food intake as precisely as possible for three days (two weekdays and one day on the weekend) throughout the study. Total energy (kcals per day), and intakes of carbohydrates, fats and proteins (grams per day) were calculated. All dietary logs of all the subjects were assessed using Diet Analysis Plus, version 10 (Cengage, Boston, MA, USA) (Table 2).

Table 2. Mean \pm SD values of nutritional intake in the four study groups.

\begin{tabular}{|c|c|c|c|c|c|c|c|c|}
\hline & \multicolumn{2}{|c|}{$\mathrm{CP}$} & \multicolumn{2}{|c|}{$S$} & \multicolumn{2}{|c|}{ TP } & \multicolumn{2}{|c|}{ TS } \\
\hline & Pre & Post & Pre & Post & Pre & Post & Pre & Post \\
\hline $\begin{array}{l}\text { Energy } \\
\text { (kcal/d) }\end{array}$ & $2364.5 \pm 164.6$ & $2383.1 \pm 106.6$ & $2370.1 \pm 162.9$ & $2385.6 \pm 157.0$ & $2362.1 \pm 214.2$ & $2340.3 \pm 213.4$ & $2393.6 \pm 215.5$ & $2358.0 \pm 193.2$ \\
\hline $\mathrm{CHO}(\mathrm{g} / \mathrm{d})$ & $295.1 \pm 24.0$ & $305.1 \pm 36.1$ & $298.0 \pm 33.1$ & $304.6 \pm 34.8$ & $289.0 \pm 31.5$ & $291.6 \pm 29.5$ & $292.7 \pm 31.9$ & $295.0 \pm 32.4$ \\
\hline Fat $(g / d)$ & $79.8 \pm 16.8$ & $77.0 \pm 15.7$ & $79.6 \pm 15.8$ & $76.9 \pm 14.2$ & $81.4 \pm 16.0$ & $78.9 \pm 14.5$ & $83.8 \pm 17.0$ & $79.1 \pm 14.6$ \\
\hline Protein (g/d) & $116.3 \pm 16.9$ & $117.3 \pm 17$ & $115.3 \pm 19.2$ & $118.7 \pm 19.2$ & $118.2 \pm 17.4$ & $115.9 \pm 18.7$ & $117.0 \pm 18.9$ & $116.3 \pm 17.8$ \\
\hline
\end{tabular}

CP, Control-Placebo; S, Supplement; TP, Training-Placebo; TS, Training-Supplement; CHO, carbohydrate.

\subsection{Supplementation Protocol}

The broccoli sprouts supplement was purchased as a powder from Cyvex Nutrition Company (Irvine, CA, USA). The sulforaphane content of the broccoli supplements (BroccoPhane) was $\sim 22.5 \mathrm{mmol} / \mathrm{g}$, as determined by the manufacturer using a high-performance liquid chromatography method. The dose of sulforaphane used in this study was $225 \mu \mathrm{mol}$ per $10 \mathrm{~g} / \mathrm{d}$ of broccoli sprouts powder supplement. Both participants and researchers were blinded to supplement allocations, and a dietitian who was not in the study conducted the allocations of broccoli supplement and placebo to the groups. The two broccoli groups (TS and S) received a monthly supply of 30 packets (containing $10 \mathrm{~g}$ broccoli supplement) for the study duration. Participants were instructed to consume one packet of broccoli supplement powder after a daily meal (preferably with a beverage to reduce gastrointestinal complications) for 12 weeks. The two other placebo groups (TP and CP) consumed $5 \mathrm{~g}$ of cornstarch powder which was colored with spinach powder (ratio of 10:1) with a beverage daily. The volume, flavor, and color of the placebo were matched with the broccoli supplements. All participants were asked to maintain a regular diet and lifestyle. Moreover, participants were examined for possible side effects by a nutritionist every week 
during the 12 week study period. Patients who reported side effects or consumed less than $80 \%$ of the packets or changed their medications were excluded from the study.

\subsection{Biochemical Analysis}

Blood samples $(10 \mathrm{cc})$ were taken from an indwelling cannula in the antecubital vein of seated subjects. Samples were collected in tubes containing EDTA (ethylenediaminetetraacetic acid) and then centrifuged at $3500 \mathrm{rpm}$ for $15 \mathrm{~min}$ at $4{ }^{\circ} \mathrm{C}$. Plasma concentrations of insulin were determined using a commercially available radioimmunoassay kit (Diagnostic Systems Laboratories, Webster, TX, USA), while plasma glucose concentrations were measured with a colorimetric-enzyme (glucose oxidase) method using glucose assay kits (Pars Tests Company Kit, Tehran, Iran) with a $1 \mathrm{mg} / \mathrm{dL}$ sensitivity. The HOMA-IR model was used to measure insulin resistance, where the insulin resistance index $=$ fasting plasma glucose $(\mathrm{mmol} / \mathrm{L}) \times$ fasting serum insulin $(\mu \mathrm{U} / \mathrm{mL}) / 22.5$ [29]. Plasma levels of dectin-1 were measured using an ELISA kit (RayBiotech Company, Germany) having a sensitivity of $0.082 \mathrm{ng} / \mathrm{mL}$. Plasma triglycerides (TG), high-density lipoprotein (HDL), low-density lipoprotein (LDL), total cholesterol (TC) levels were measured with a standard biochemical analyzer (DAX 96; Bayern Diagnostics, Milan, Italy). The serum concentration of high sensitive $C$ reactive protein (hs-CRP) was evaluated by using an enzyme-linked immunosorbent assay (ELISA) kit (Diagnostics Biochem Canada Inc., London, ON, Canada). Tumor necrosis factor- $\alpha$ (TNF- $\alpha$ ) and interleukin-6 (IL-6) levels were assessed with ELISA kits (Diaclone, Besancon, France). The coefficients of variation were $1.2 \%$ for glucose, $1.8 \%$ for insulin, $2.9 \%$ for HOMA-IR, $3.1 .0 \%$ for dectin- $1,2.4 \%$ for HDL, LDL, TC, TG and $<5 \%$. For hs-CRP, TNF- $\alpha$ and IL-6.

\subsection{Statistical Analysis}

Data are presented as the mean \pm standard deviation (mean \pm SD). All statistical analyses were computed using IBM SPSS statistical software (Version 23.0; SPSS, Inc., Chicago, IL, USA). The normality of the data was assessed with the Shapiro-Wilk test. The Leven test showed that the homogeneity of variances was present $(p>0.05)$. Baseline data were compared between the four groups using one-way ANOVA tests and Tukey's post hoc tests. A repeated measures test of ANOVA (group $\times$ time) was used to compare differences in biochemical, body composition markers and dietary variables (total energy in kcal per day, intake of carbohydrates, fats, and proteins) between the four groups. If an ANOVA test determined significant differences, pairwise comparisons (planned comparisons) were used to determine which mean differences were statistically significant. Statistical significance was established at $p \leq 0.05$. Effect size (ES) was assessed by partial eta-squared $\left(\begin{array}{c}p \\ 2\end{array}\right)$ and repeated measures ANOVA was used to determine statistical power $(1-\beta)$. The sample size was designed to detect a difference in study variables with a $95 \%$ confidence interval $(\mathrm{CI})$ and $\geq 80 \%$ power value.

\section{Results}

In all study groups (CP, $\mathrm{S}, \mathrm{TP}$, and TS), no significant differences $(p>0.05)$ were observed for age, body mass, BMI, FFM, fat, duration of diabetes, blood pressure (i.e., hypertension), and antidiabetic medications (Table 3). Moreover, there were no significant differences $(p>0.05)$ between the groups for study clinical and biochemical variables at baseline (Table 3).

\subsection{Dietary Analysis}

There were no differences between groups in total energy consumption and energy derived from carbohydrate, fat and protein at baseline and after 12 weeks $(p>0.05)$ (Table 2). 
Table 3. Mean \pm SD values of glucose, lipid profile, inflammatory markers, body composition and $\mathrm{VO}_{2 \text { peak }}$ for the four study groups.

\begin{tabular}{|c|c|c|c|c|c|c|c|c|}
\hline & \multicolumn{2}{|c|}{$\mathrm{CP}$} & \multicolumn{2}{|c|}{$\mathrm{S}$} & \multicolumn{2}{|c|}{ TP } & \multicolumn{2}{|c|}{ TS } \\
\hline & Pre & Post & Pre & Post & Pre & Post & Pre & Post \\
\hline $\begin{array}{c}\text { Glucose } \\
(\mathrm{mmol} / \mathrm{L})\end{array}$ & $8.71 \pm 0.73$ & $8.58 \pm 0.65$ & $8.78 \pm 0.75$ & $7.89 \pm 0.75 \ddagger$ & $8.79 \pm 0.71$ & $6.38 \pm 0.47^{\ddagger * \#}$ & $8.86 \pm 0.71$ & $5.94 \pm 0.54^{\ddagger * \#}$ \\
\hline $\begin{array}{l}\text { HDL-C } \\
(\mathrm{mmol} / \mathrm{L})\end{array}$ & $0.84 \pm 0.05$ & $0.84 \pm 0.03$ & $0.94 \pm 0.04$ & $0.99 \pm 0.04^{\ddagger *}$ & $0.92 \pm 0.06$ & $1.16 \pm 0.09 \ddagger * \#$ & $0.90 \pm 0.06$ & 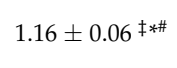 \\
\hline LDL (mmol/L) & $4.11 \pm 0.12$ & $4.08 \pm 0.12$ & $4.06 \pm 0.13$ & $3.98 \pm 0.20 \ddagger$ & $4.11 \pm 0.12$ & $3.74 \pm 0.13^{\ddagger *}$ & $4.20 \pm 0.12$ & $3.46 \pm 0.21^{\text {f*\# }}$ \\
\hline $\mathrm{TC}(\mathrm{mmol} / \mathrm{L})$ & $6.20 \pm 0.25$ & $6.23 \pm 0.26$ & $6.07 \pm 0.26$ & $5.99 \pm 0.28 \ddagger$ & $6.05 \pm 0.24$ & $5.43 \pm 0.23^{\ddagger * \#}$ & $6.12 \pm 0.28$ & $5.32 \pm 0.23^{\text {‡*\# }}$ \\
\hline TG (mmol/L) & $6.20 \pm 0.023$ & $6.20 \pm 0.28$ & $2.23 \pm 0.28$ & $6.10 \pm 0.28 \ddagger$ & $6.12 \pm 0.29$ & $5.64 \pm 0.366^{\ddagger *}$ & $6.23 \pm 0.29$ & $5.43 \pm 0.34_{\text {f*\# }}$ \\
\hline $\begin{array}{l}\text { hs-CRP } \\
\text { (ng/mL) }\end{array}$ & $4.20 \pm 1.02$ & $4.25 \pm 1.04$ & $4.51 \pm 1.84$ & $3.75 \pm 1.62 \ddagger$ & $4.53 \pm 1.16$ & $3.05 \pm 1.01 \ddagger$ & $4.22 \pm 1.21$ & $2.48 \pm 0.56^{\ddagger}$ \\
\hline IL-6 (pg/mL) & $4.89 \pm 0.90$ & $4.96 \pm 1.09$ & $4.90 \pm 1.59$ & $4.59 \pm 1.34 \ddagger$ & $4.98 \pm 1.05$ & $2.85 \pm 1.01^{\ddagger *}$ & $5.22 \pm 1.21$ & $2.64 \pm 2.01^{\ddagger *}$ \\
\hline $\begin{array}{l}\text { TNF- } \alpha \\
(\mathrm{pg} / \mathrm{mL})\end{array}$ & $14.60 \pm 3.18$ & $14.78 \pm 3.29$ & $14.97 \pm 4.32$ & $13.45 \pm 3.89 \ddagger$ & $14.55 \pm 4.36$ & $11.53 \pm 3.56^{\ddagger}$ & $14.97 \pm 3.80$ & $7.78 \pm 2.63^{\ddagger *}$ \\
\hline Weight (kg) & $86.36 \pm 4.56$ & $86.72 \pm 3.90$ & $85.00 \pm 3.31$ & $85.18 \pm 3.57$ & $86.09 \pm 4.41$ & $79.90 \pm 3.53^{\ddagger *}$ & $86.63 \pm 4.90$ & $79.09 \pm 3.78^{\ddagger *}$ \\
\hline FFM (kg) & $28.36 \pm 1.56$ & $28.27 \pm 1.84$ & $29.63 \pm 2.06$ & $29.45 \pm 2.29$ & $28.90 \pm 1.44$ & $32.27 \pm 2.05^{\ddagger *}$ & $28.72 \pm 1.73$ & $32.09 \pm 2.30^{\ddagger *}$ \\
\hline Fat (\%) & $29.54 \pm 1.12$ & $29.63 \pm 2.50$ & $29.81 \pm 2.04$ & $29.45 \pm 1.91$ & $29.54 \pm 1.75$ & $25.90 \pm 1.81$ †*\# & $30.18 \pm 1.83$ & $25.09 \pm 2.21$ ‡*\# \\
\hline BMI $\left(\mathrm{kg} / \mathrm{m}^{2}\right)$ & $28.34 \pm 1.13$ & $28.46 \pm 0.96$ & $27.38 \pm 1.34$ & $27.43 \pm 1.33$ & $28.51 \pm 0.84$ & $27.29 \pm 0.74^{\ddagger}$ & $28.06 \pm 0.82$ & $26.17 \pm 0.78^{\ddagger *}$ \\
\hline $\begin{array}{c}\mathrm{VO}_{2 \text { peak }} \\
(\mathrm{mL} / \mathrm{kg} / \mathrm{min})\end{array}$ & $28.09 \pm 1.97$ & $27.63 \pm 2.29$ & $28.27 \pm 2.45$ & $28.36 \pm 2.33$ & $28.81 \pm 3.45$ & $32.90 \pm 3.91$ ‡*\# & $28.09 \pm 2.42$ & $33.36 \pm 0.69$ ‡*\# \\
\hline
\end{tabular}

CP, Control-Placebo; S, Supplement; TP, Training-Placebo; TS, Training-Supplement; HDL, high-density lipoprotein; LDL, low-density lipoprotein; TC, total cholesterol; TG, triglyceride; hs-CRP, high-sensitivity C-reactive protein; IL-6, interleukin-6; TNF- $\alpha$, tumor necrosis factor- $\alpha$. FFM, fat free mass; FM, fat mass; BMI, body mass index. * indicates significant differences compared to the control group $(p<0.05)$.

$\#$ indicates significant differences compared to $S$ group $(p<0.05) .{ }^{\ddagger}$ indicated significant difference from baseline $(p<0.05)$.

\subsection{Dectin-1, CRP, IL-6 and TNF- $\alpha$}

A significant interaction (group $\mathrm{X}$ time) was observed for dectin-1 $(\mathrm{F} 3,40=13.6$, $p=0.0001$, ES $=0.50$, power $=1.0)$, hs-CRP $(\mathrm{F} 3,40=25.1, p=0.0001$, ES $=0.65$, power $=1.0)$, IL-6 $(\mathrm{F} 3,40=42.1, p=0.0001$, ES $=0.76$, power $=1.0)$, and TNF- $\alpha(\mathrm{F} 3,40=40.3, p=0.0001$, $\mathrm{ES}=0.75$, power $=1.0)$. Plasma levels of dectin- 1 were decreased in the $\mathrm{S}$, TS and TP groups compared to the $\mathrm{CP}$ group $(p<0.05)$ (Figure 3$)$. However, the decrease in the $\mathrm{S}$ group was not significant $(p>0.05)$ when compared to the CP group. The reduction in hs-CRP concentrations in TS, TP and S groups were not significant $(p>0.05)$ compared to the CP group (Table 3). Levels of IL-6 decreased $(p<0.05)$ in both TS, and TP groups when compared to the CP group (Table 3). However, there were no changes $(p>0.05)$ in the $S$ group compared to the CP group (Table 3). TNF- $\alpha$ levels were reduced $(p<0.05)$ in the TS group when compared to the $\mathrm{CP}$ group, but these reductions in TP and $\mathrm{S}$ groups were not significant $(p>0.05)$ when compared with the CP group (Table 3). Paired t-tests showed decreases $(p<0.05)$ for hs-CRP, IL-6 and TNF- $\alpha$ levels after 12 weeks (compared to baseline) in the TS, TP and S groups (Table 3 ).

\subsection{Insulin, HOMA-IR and Glucose}

An interaction was observed between group and time for insulin (F3, $40=73.5$, $p=0.0001, \mathrm{ES}=0.85$, power $=1.0)$ HOMA-IR $(\mathrm{F} 3,40=98.7, p=0.0001, \mathrm{ES}=0.88$, power $=1.0)$ and glucose $(\mathrm{F} 3,40=52.5, p=0.0001$, ES $=0.79$, power $=1.0)$. There were reductions $(p<0.05)$ in the levels of insulin, HOMA-IR and glucose in the TS, TP groups compared to the $\mathrm{S}$ and $\mathrm{CP}$ group (Figures 4 and 5, Table 3). Nevertheless, these decreases were not significant $(p>0.05)$ in the $S$ group when compared with the CP group (Figures 4 and 5 , Table 3). Levels of dectin-1, insulin, HOMA-IR, and glucose were decreased $(p<0.05)$ after 12 weeks when compared to baseline values in the TS, TP and S groups. 
$\square$ Pre $\quad$ Post

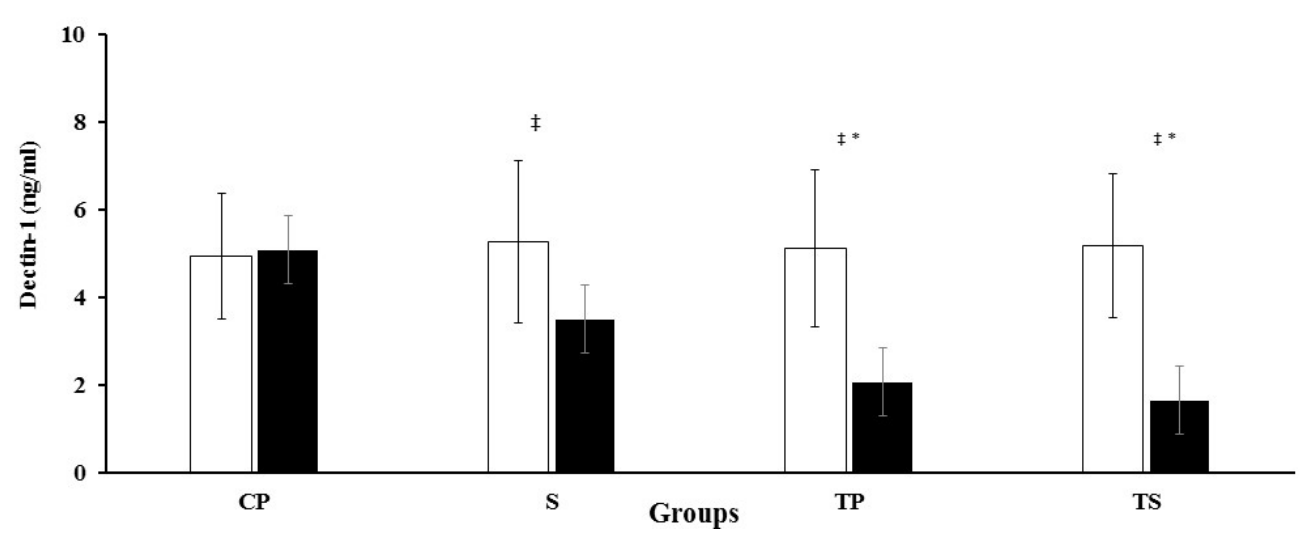

Figure 3. Pre and post training values (mean \pm SD) for 3 Dectin-1. CP, Control-Placebo; S, Supplement; TP, Training-Placebo; TS, Training-Supplement groups. * indicates significant differences compared to the control group $(p<0.05)$. $\ddagger$ indicated significant difference from baseline $(p<0.05)$.

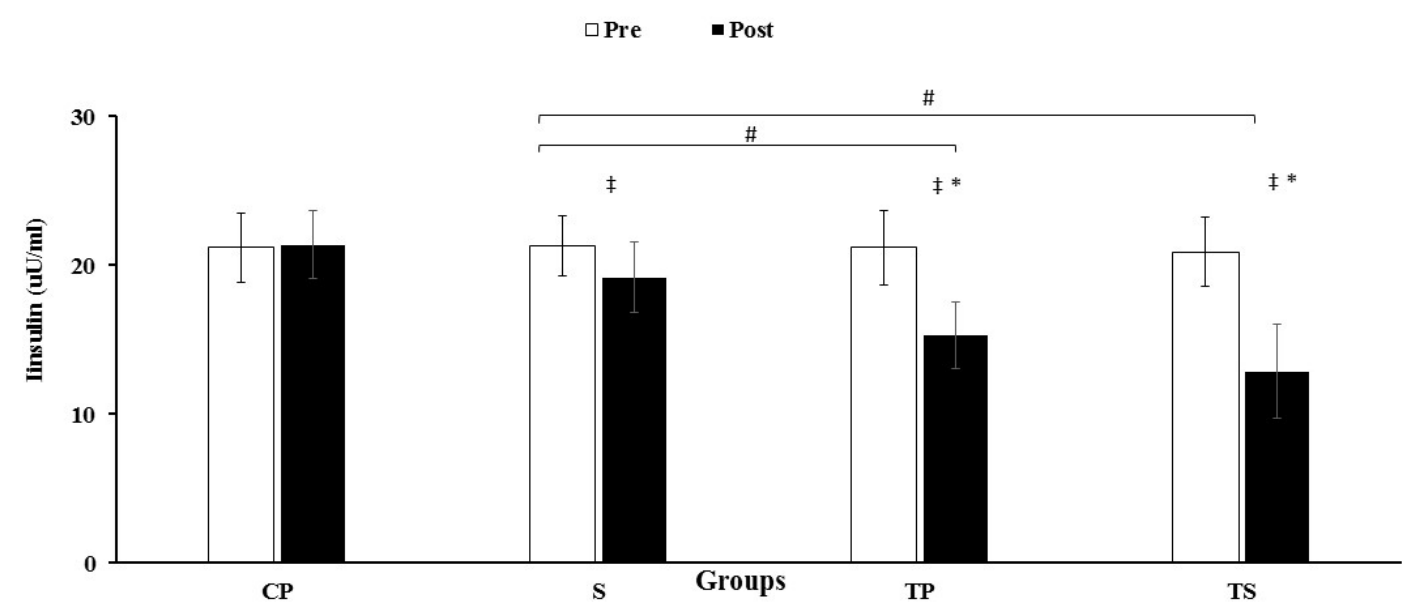

Figure 4. Pre and post training values (mean $\pm \mathrm{SD}$ ) for insulin in $\mathrm{CP}$, Control-Placebo; S, Supplement; TP, Training-Placebo; TS, Training-Supplement groups. * indicates significant differences with control group $(p<0.05)$. ${ }^{*}$ indicates significant differences compared to the control group $(p<0.05)$. \# indicated significant differences compared to $S$ group $(p<0.05)$. $\ddagger$ indicated significant difference from baseline $(p<0.05)$.

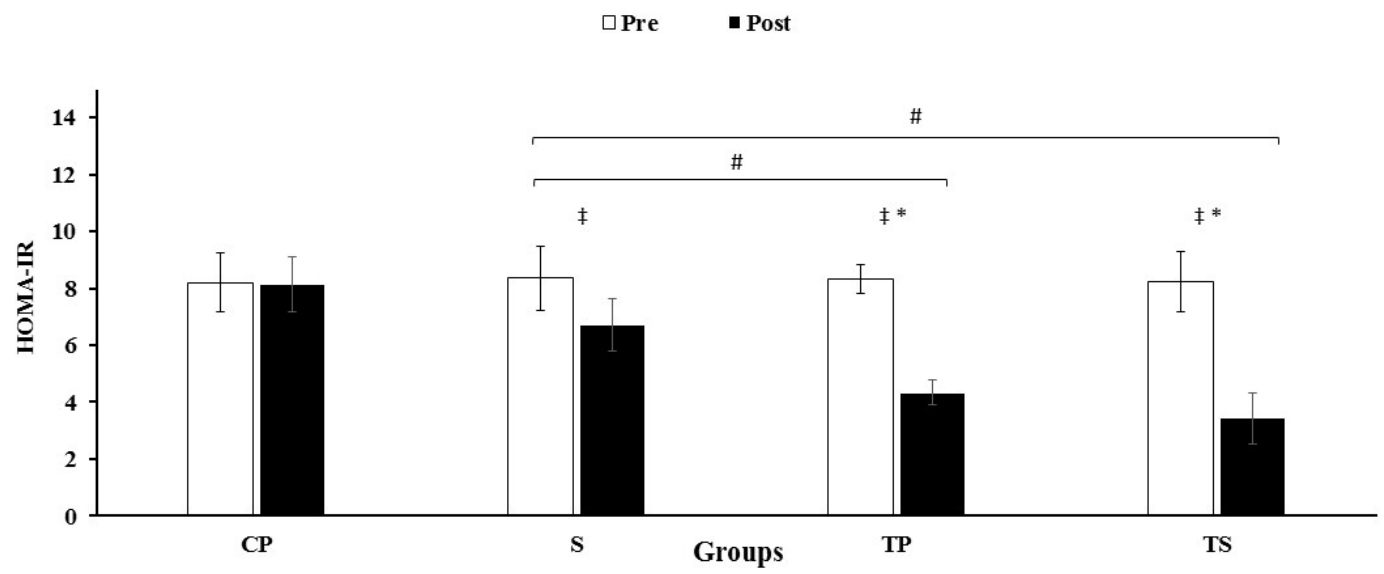

Figure 5. Pre and post training values (mean \pm SD) for HOMA-IR in CP, Control-Placebo; S: Supplement; TP, TrainingPlacebo; TS, Training-Supplement groups. ${ }^{*}$ indicates significant differences with control group $(p<0.05)$. ${ }^{*}$ indicates significant differences compared to the control group $(p<0.05)$. \# indicated significant differences compared to $S$ group $(p<0.05) . \ddagger$ indicated significant difference from baseline $(p<0.05)$. 


\subsection{Lipid Profiles}

There was an interaction between group and time for HDL (F3, 40 $=44.6, p=0.0001$, $\mathrm{ES}=0.77$, power $=1.0)$, LDL $(\mathrm{F} 3,40=82.5, p=0.0001, \mathrm{ES}=0.86$, power $=1.0)$, $\mathrm{TC}(\mathrm{F} 3$, $40=325.3, p=0.0001$, ES $=0.96$, power $=1.0)$ and TG $(\mathrm{F} 3,40=228.3, p=0.0001, \mathrm{ES}=0.94$, power $=1.0$ ). Plasma levels of HDL were increased in the TS, TP and $S$ groups compared with the CP group $(p<0.05)$. However, this increase was greater in the TS and TP groups compared with the $S$ group $(p<0.05)$ (Table 3$)$. Plasma levels of LDL, TC and TG were decreased after 12 weeks in both the TS and TP groups compared to the CP group $(p<0.05)$ (Table 3). Nevertheless, these decreases for LDL and TG were greater $(p<0.05)$ in the TS group compared to the $S$ group. No changes were observed for LDL, TC and TG in the $\mathrm{S}$ group when compared to the $\mathrm{CP}$ group $(p>0.05)$ (Table 3). A paired sample $t$-test indicated an increase $(p<0.05)$ in HDL and also decreases $(p<0.05)$ for LDL, TC and TG from baseline to post measurements after 12 weeks in the TS, TP and S groups (Table 3).

\subsection{Body Composition Variables and $V \mathrm{O}_{2 p e a k}$}

There was an interaction between group and time for weight (F3, 40 $=84.0, p=0.0001$, ES: 0.86 , power:1.0), \% body fat (F3, $40=40.5, p=0.0001$, ES: 0.75 , power:1.0), BMI (F3, $40=62.1, p=0.0001$, ES: 0.82, power:1.0), FFM (F3, $40=22.5, p=0.0001$, ES: 0.62, power:1.0), and $\mathrm{VO}_{2}$ peak $(\mathrm{F} 3,40=109.8, p=0.0001$, ES: 0.89 , power:1.0) $(p<0.05)$. There were reductions in weight in the TS and TP groups compared to the CP group $(p<0.05)$. However, no changes in body weight were observed in the S group compared to CP group $(p>0.05)$ (Table 3). There were reductions in body fat $\%$ in both the TS and TP groups $(p<0.05)$ compared to the $\mathrm{S}$ and $\mathrm{CP}$ groups (Table 3). Body fat percent changes in the $\mathrm{S}$ group in comparison with the $\mathrm{CP}$ group were not significant $(p>0.05)$ after 12 weeks. Only the TS group had a reduction $(p<0.05)$ in BMI when compared to the CP group (Table 3$)$. The decreases in the TP and S groups were not significant $(p>0.05)$ when compared to CP group (Table 3). Fat free mass in the both the TS and TP groups were increased $(p<0.05)$ compared with the $\mathrm{CP}$ group after 12 weeks of training (Table 3), while there were no changes in the $\mathrm{S}$ group $(p>0.05)$ compared to the $\mathrm{CP}$ group after 12 weeks (Table 3$)$. Values for $\mathrm{VO}_{2 \text { peak }}$ were increased after 12 weeks in the TS and TP groups compared with the $\mathrm{CP}$ and $\mathrm{S}$ groups $(p<0.05)$ (Table 3$)$. There were significant changes in weight, body fat $\%$, BMI, FFM, and $\mathrm{VO}_{2 \text { peak }}$ from baseline to 12 weeks in the TS and TP groups $(p<0.05)$ (Table 3).

\section{Discussion}

This study indicates that plasma levels of dectin-1, HOMA-IR, insulin, and selected adipokines such as TNF- $\alpha$ and IL- 6 as well as hs-CRP were improved after 12 weeks in the S, TS and TP groups compared to their base levels, with greater improvements in the TS group. In addition, improvements in the lipid profile, insulin levels, body composition variables, and $\mathrm{VO}_{2 \text { peak }}$ were observed only in the TS and TP groups.

We report that dectin-1 was decreased in the TS, TP, and S groups, but that there were greater improvements in the TS $(-70 \%)$ and TP $(-60 \%)$ groups compared to their baseline levels. A study by Ruffino et al. (2016) indicated that eight-weeks of a moderate-intensity exercise program (walking for $45 \mathrm{~min}, 3 \mathrm{~d} / \mathrm{w}$ ) increased dectin-1 levels and other monocyte M2 markers in overweight females [30]. In addition, not only did we find a significant decrease in dectin-1 levels in the supplement group, but also that the improvement in the TS group was greater (but non-significant) than in the TP group, suggesting additional benefits of broccoli supplement + exercise training in altering dectin-1 levels.

Activation of dectin-1 induces the production of pro-inflammatory cytokines, chemokines [6], and reactive oxygen species [7]. We measured reductions in adipokines such as TNF- $\alpha$ and IL- 6 as well as hs-CRP after 12 weeks in the S, TP and, TS groups when compared to their baseline levels, with non-significant decreases in the TS group compared to $S$ and TP groups. These results support other studies reporting beneficial effects of CARET on inflammatory markers in individuals with metabolic syndrome disorders [31,32]. For example, it is shown that 16-weeks of CARET (aerobic intensity: $40 \%$ to $65 \%$ of heart 
rate reserve, resistance intensity: $40 \%$ to $60 \%$ of $1-\mathrm{RM}$, three times/week) reduced TNF- $\alpha$ and IL-6 levels in individuals with T2D [21]. The potential explanation for this alteration is that changes in IL-6 produced by exercising muscles could elevate anti-inflammatory cytokines such as IL-10 and interleukin-1 receptor antagonist (IL-1RA), which are able to decrease TNF- $\alpha$ levels to a significant level [21]. A recent study reported that ingestion of sulforaphane (50 mg/ kg body weight) decreased the expression of some adipokines, e.g., IL- 6 and TNF- $\alpha$ and blood biomarkers of tissue damage or cell death (alanine aminotransferase, aspartate aminotransferase, and lactate dehydrogenase) following exercise to exhaustion in male mice [33]. In addition, 10 weeks of consuming broccoli sprouts (30 g per day) improved inflammatory markers in healthy but overweight individuals [34]. Our study suggests that not only can broccoli supplement alone improve pro-inflammatory factors compared to their baseline levels, but also broccoli supplement + CARET may have additional beneficial (but non-significant) effects on improving pro-inflammatory factors such as dectin-1. The potential explanation for this improvement could be related to the finding that the consumption of sulforaphane suppresses NLRP3 (which is predominantly expressed in macrophages and triggers immune responses), and which then decreases dectin-1 levels and other pro-inflammatory factors in individuals with T2D [35]. Taken together, consuming broccoli and doing CARET can have synergistic beneficial effects on pro-inflammatory factors. In line with this, we found greater improvements in TNF- $\alpha$ $(-48 \%)$ and IL-6 $(-49 \%)$ as well as dectin-1 $(-70 \%)$ levels in the TS group compared to their baseline levels. However, we did not find significant differences in pro-inflammatory factors between the $S$ and CP groups; therefore, additional experiments are needed to better define the underlying mechanisms of improvements in inflammatory factors, particularly dectin-1, following consumption of broccoli supplement.

Our study also shows that insulin and insulin resistance (HOMA-IR) levels decreased in the S, TP, and TS groups, compared to their baseline levels with the greatest improvement in the TS group. CARET is a more potent exercise modality in improving insulin and glucose uptake in individuals with T2D [36-38], likely because of the different mechanisms of CARET [17,36,38]. For example, the activation of larger groups of muscle mass compared to resistance training or aerobic training alone, leading to greater improvements in insulin resistance and glucose uptake $[17,38]$. Additionally, improvement in insulin and glucose could be partly due to increased muscle mass and GLUT-4 induced by CARET [39]. We also measured improvements in insulin and HOMA-IR in the S and TS groups when compared with their baseline levels, with the improvements caused by broccoli consumption similar to findings in other studies $[10,12]$. Recent findings have suggested that IL- 6 gene expression is mildly elevated in individuals with insulin resistance [40]. Furthermore, the C-174C genotype of the IL-6 gene is associated with insulin resistance in normoglycemic individuals [41]. In addition, Insulin signaling and secretion are reduced by decreasing TNF- $\alpha$ levels [42], and insulin resistance is directly related to TNF- $\alpha$ levels [38,43]. However, both CARET and broccoli can improve insulin resistance through improving IL-6 levels, decreased levels of pro-inflammatory cytokines, and reduction in body fat percentage, stimulates an anabolic and anti-inflammatory pathway that preserves lean body mass and improves insulin resistance in T2D. The largest improvements in insulin and HOMA-IR were in the TS group. One of the main reasons is that strengthening antioxidant defenses is important in inhibiting the activation of signaling pathways such as nuclear factor kappa B and extracellular signal-related kinases that cause insulin resistance [44]. Sulforaphane is an important bioactive component of broccoli supplement, which leads to lipid peroxidation and increases total antioxidant capacity [10]. Sulforaphane activates the transcription Nrf-2 (NF-E2-related factor 2) to regulate cellular redox homoeostasis by increasing the expression of enzymes that detoxify reactive oxygen species $[45,46]$. Thus, enhancing the endogenous antioxidant network with broccoli supplementation can suppress stress-sensitive signaling pathways and improve glucose uptake, insulin, and HOMA-IR and other long-term complications in individuals with T2D [10]. 
Our study also reports improvements in the lipid profiles in the S, TP, and TS groups compared with their baseline levels; however, our study failed to improve lipid profiles, except for HDL-C, in the $\mathrm{S}$ group when compared to the $\mathrm{CP}$ group. Broccoli supplementation decreases plasma LDL-C via regulation of the redox status of cells and tissues, leading to enhanced the activity of AMP-activated protein kinase (AMPK) signaling and suppression of Phosphoinositide 3-kinases (PI3K) signaling [47]. Additionally, aerobic exercise combined with weight loss reduces blood cholesterol, LDL-C, and triglycerides and also HDL-C [48]. Improvements in lipid profiles occur during weight loss in individuals with overweight/obesity $[49,50]$. A study by Varady et al. (2011) reported decreases in LDL levels following a calorie restriction diet, with no reductions in LDL levels after 12 weeks of moderate-intensity exercise training (three days per week, $45 \mathrm{~min}, 60 \% \mathrm{HRmax}$ ) [50]. We report greater weight loss (TS-12\%, TP-7\%), with our exercise program causing a higher stimulation and greater improvements in lipid profiles.

Although we tried to control energy expenditure in all the groups, body composition variables did not differ in the $\mathrm{CP}$ and $\mathrm{S}$ groups. However, body composition variables (BMI, fat $\%$ and fat free mass) were improved in the TP and TS groups, likely because CARET is a potent strategy for reducing body weight and fat mass percentage, as this exercise modality requires more energy expenditure and a higher rate of excess postexercise oxygen consumption [17]. Additionally, a study by Lopez-Chillon et al. (2019) reported that 10 weeks of consuming broccoli sprouts ( $30 \mathrm{~g} /$ day) altered body fat levels in individuals with obesity, possibly because broccoli supplement induces an alteration in indole-3-carbinol, which decreases adipogenesis by suppressing pathways of lipid accumulation mediated by PPAR $\gamma$ [34]. However, we did not find an improvement in body composition variables in the $S$ group that might stem from the dosage of supplement and/or the lack of energy intake control in our study.

Our study has several limitations. Firstly, we did not identify the mechanisms by which bioactive components of broccoli can improve dectin-1 levels. Second, our study cannot be generalized as females were not included in patient recruitment. In addition, we did not control dietary and energy expenditure, which could affect many of the physiologic variables that can modulate adipokines release. Finally, our study did not include a more heterogeneous group of individuals diagnosed with T2D.

\section{Conclusions}

This study reports that the inclusion of broccoli supplementation to a CARET program for individuals with T2D leads to greater improvements in dectin-1 levels and body composition, cardiorespiratory fitness, lipid profiles, glycemic control, and insulin resistance compared to their baseline levels. Our findings suggest that a combination of broccoli supplement with CARET has additive beneficial effects in individuals with T2D. An important finding of our study is that supplementing with broccoli and CARET causes greater elevations in $\mathrm{VO}_{2 \text { peak }}$ in patients with T2D.

Author Contributions: A.S.: conceptualization, data collection, formal analysis. M.S.: statistical analysis and conceptualization. A.D.: data interpretation, manuscript preparation, and literature search. H.N.: data interpretation, manuscript preparation, and literature search. M.M.H.: investigation, data collection, and conceptualization. N.K.: investigation and conceptualization. K.E.J.: resources and data interpretation. K.E.J., I.L. and A.C.H.: resources and data interpretation, supervision. H.Z. and T.A.V.: supervision, writing-original draft. All authors have read and agreed to the published version of the manuscript.

Funding: This research received no external funding.

Institutional Review Board Statement: The study was conducted according to the guidelines of the Declaration of Helsinki, and approved by the Institutional Review Board of Islamic Azad Damghan University (Ethics code: IR-IAU1397-3).

Informed Consent Statement: Informed consent was obtained from all subjects involved in the study. 
Data Availability Statement: The datasets generated for this study are available on request to the corresponding author.

Acknowledgments: The authors would like to thank all patients who generously contributed to this study. This research did not receive any specific grant from funding agencies in the public, commercial, or not-for-profit sectors.

Conflicts of Interest: The authors declare no conflict of interest.

Ethics Statement: All participants gave their written, informed consent to participate in the study prior to its commencement. All participants gave their written, informed consent for publication. All study procedures and protocols were approved by the local University Research and Ethics Committee and performed according to the latest revision of the Declaration of Helsinki.

\section{References}

1. Wu, Y.; Ding, Y.; Tanaka, Y.; Zhang, W. Risk factors contributing to type 2 diabetes and recent advances in the treatment and prevention. Int. J. Med. Sci. 2014, 11, 1185-1200. [CrossRef]

2. Joseph, J.J.; Echouffo-Tcheugui, J.B.; Golden, S.H.; Chen, H.; Jenny, N.S.; Carnethon, M.R.; Jacobs, D.; Burke, G.L.; Vaidya, D.; Ouyang, P.; et al. Physical activity, sedentary behaviors and the incidence of type 2 diabetes mellitus: The Multi-Ethnic Study of Atherosclerosis (MESA). BMJ Open Diabetes Res. Care 2016, 4, e000185. [CrossRef] [PubMed]

3. de Oliveira Otto, M.C.; Padhye, N.S.; Bertoni, A.G.; Jacobs, D.R., Jr.; Mozaffarian, D. Everything in moderation-dietary diversity and quality, central obesity and risk of diabetes. PLoS ONE 2015, 10, e0141341. [CrossRef] [PubMed]

4. Dandona, P.; Aljada, A.; Bandyopadhyay, A. Inflammation: The link between insulin resistance, obesity and diabetes. Trends Immunol. 2004, 25, 4-7. [CrossRef] [PubMed]

5. Cortez-Espinosa, N.; García-Hernández, M.H.; Reynaga-Hernández, E.; Cortés-García, J.D.; Corral-Fernández, N.E.; RodríguezRivera, J.G.; Bravo-Ramírez, A.; González-Amaro, R.; Portales-Pérez, D. Abnormal expression and function of Dectin-1 receptor in type 2 diabetes mellitus patients with poor glycemic control (HbA1c >8\%). Metabolism 2012, 61, 1538-1546. [CrossRef]

6. Rosas, M.; Liddiard, K.; Kimberg, M.; Faro-Trindade, I.; McDonald, J.U.; Williams, D.L.; Brown, G.; Taylor, P. The induction of inflammation by dectin-1 in vivo is dependent on myeloid cell programming and the progression of phagocytosis. J. Immunol. 2008, 181, 3549-3557. [CrossRef] [PubMed]

7. Underhill, D.M.; Rossnagle, E.; Lowell, C.A.; Simmons, R.M. Dectin-1 activates Syk tyrosine kinase in a dynamic subset of macrophages for reactive oxygen production. Blood 2005, 106, 2543-2550. [CrossRef]

8. Castoldi, A.; Andrade-Oliveira, V.; Aguiar, C.F.; Amano, M.T.; Lee, J.; Miyagi, M.T.; Latância, M.T.; Braga, T.; da Silva, M.B.; Ignácio, A.; et al. Dectin-1 activation exacerbates obesity and insulin resistance in the absence of MyD88. Cell Rep. 2017, 19, 2272-2288. [CrossRef]

9. Nestle, M. Broccoli sprouts as inducers of carcinogen-detoxifying enzyme systems: Clinical, dietary, and policy implications. Proc. Natl. Acad. Sci. USA 1997, 94, 11149-11151. [CrossRef]

10. Bahadoran, Z.; Mirmiran, P.; Azizi, F. Potential efficacy of broccoli sprouts as a unique supplement for management of type 2 diabetes and its complications. J. Med. Food 2013, 16, 375-382. [CrossRef]

11. Mirmiran, P.; Bahadoran, Z.; Hosseinpanah, F.; Keyzad, A.; Azizi, F. Effects of broccoli sprout with high sulforaphane concentration on inflammatory markers in type 2 diabetic patients: A randomized double-blind placebo-controlled clinical trial. J. Funct. Foods 2012, 4, 837-841. [CrossRef]

12. Bahadoran, Z.; Mirmiran, P.; Hosseinpanah, F.; Hedayati, M.; Hosseinpour-Niazi, S.; Azizi, F. Broccoli sprouts reduce oxidative stress in type 2 diabetes: A randomized double-blind clinical trial. Eur. J. Clin. Nutr. 2011, 65, 972-977. [CrossRef]

13. Ruhee, R.T.; Suzuki, K. The integrative role of sulforaphane in preventing inflammation, oxidative stress and fatigue: A review of a potential protective phytochemical. Antioxidants 2020, 9, 521. [CrossRef] [PubMed]

14. Oh, S.; Komine, S.; Warabi, E.; Akiyama, K.; Ishii, A.; Ishige, K.; Mizokami, Y.; Kuga, K.; Horie, M.; Miwa, Y.; et al. Nuclear factor (erythroid derived 2)-like 2 activation increases exercise endurance capacity via redox modulation in skeletal muscles. Sci. Rep. 2017, 7, 1-11.

15. Malaguti, M.; Angeloni, C.; Garatachea, N.; Baldini, M.; Leoncini, E.; Collado, P.S.; Teti, G.; Falconi, M.; González-Gallego, J.; Hrelia, S.; et al. Sulforaphane treatment protects skeletal muscle against damage induced by exhaustive exercise in rats. J. Appl. Physiol. 2009, 107, 1028-1036. [CrossRef]

16. Cardenia, V.; Rodriguez-Estrada, M.T.; Lorenzini, A.; Bandini, E.; Angeloni, C.; Hrelia, S.; Malaguti, M. Effect of broccoli extract enriched diet on liver cholesterol oxidation in rats subjected to exhaustive exercise. J. Steroid Biochem. Mol. Biol. 2017, 169, 137-144. [CrossRef]

17. Saeidi, A.; Haghighi, M.M.; Kolahdouzi, S.; Daraei, A.; Abderrahmane, A.B.; Essop, M.F.; Laher, I.; Hackney, A.C.; Zouhal, H. The effects of physical activity on adipokines in individuals with overweight/obesity across the lifespan: A narrative review. Obes. Rev. 2021, 22, e13090. [CrossRef]

18. Harty, P.S.; Cottet, M.L.; Malloy, J.K.; Kerksick, C.M. Nutritional and supplementation strategies to prevent and attenuate exercise-induced muscle damage: A brief review. Sports Med. Open 2019, 5, 1-17. [CrossRef] [PubMed] 
19. Cradock, K.A.; ÓLaighin, G.; Finucane, F.M.; Gainforth, H.L.; Quinlan, L.R.; Ginis, K.A.M. Behaviour change techniques targeting both diet and physical activity in type 2 diabetes: A systematic review and meta-analysis. Int. J. Behav. Nutr. Phys. Act. 2017, 14, 1-17. [CrossRef]

20. Jorge, M.L.M.P.; de Oliveira, V.N.; Resende, N.M.; Paraiso, L.F.; Calixto, A.; Diniz, A.L.D.; Resende, E.S.; Ropelle, E.; Carvalheira, J.; Espindola, F.S.; et al. The effects of aerobic, resistance, and combined exercise on metabolic control, inflammatory markers, adipocytokines, and muscle insulin signaling in patients with type 2 diabetes mellitus. Metabolism 2011, 60, 1244-1252. [CrossRef]

21. Annibalini, G.; Lucertini, F.; Agostini, D.; Vallorani, L.; Gioacchini, A.; Barbieri, E.; Guescini, M.; Casadei, L.; Passalia, A.; Del Sal, M.; et al. Concurrent aerobic and resistance training has anti-inflammatory effects and increases both plasma and leukocyte levels of IGF-1 in late middle-aged type 2 diabetic patients. Oxidative Med. Cell. Longev. 2017, 2017, 3937842. [CrossRef]

22. Lucotti, P.; Monti, L.D.; Setola, E.; Galluccio, E.; Gatti, R.; Bosi, E.; Piatti, P. Aerobic and resistance training effects compared to aerobic training alone in obese type 2 diabetic patients on diet treatment. Diabetes Res. Clin. Pract. 2011, 94, 395-403. [CrossRef] [PubMed]

23. Francois, M.E.; Pistawka, K.J.; Halperin, F.A.; Little, J.P. Cardiovascular benefits of combined interval training and post-exercise nutrition in type 2 diabetes. J. Diabetes Complicat. 2018, 32, 226-233. [CrossRef] [PubMed]

24. Herder, C.; Peltonen, M.; Koenig, W.; Sütfels, K.; Lindström, J.; Martin, S.; Ilanne-Parikka, P.; Eriksson, J.G.; Aunola, S.; KeinänenKiukaanniemi, S.; et al. Anti-inflammatory effect of lifestyle changes in the Finnish Diabetes Prevention Study. Diabetologia 2009, 52, 433-442. [CrossRef] [PubMed]

25. Nathanson, V. Revising the declaration of Helsinki. BMJ Publ. Group 2013, 346, f2837. [CrossRef]

26. Borg, G. Perceived exertion as an indicator of somatic stress. Scand. J. Rehabil. Med. 1970, 2, 92-98. [PubMed]

27. Brzycki, M. Strength testing-Predicting a one-rep max from reps-to-fatigue. J. Phys. Educ. Recreat. Danc. 1993, 64, 88-90. [CrossRef]

28. Mendes, R.; Sousa, N.; Almeida, A.; Subtil, P.; Guedes-Marques, F.; Reis, V.M.; Themudo-Barata, J.L. Exercise prescription for patients with type 2 diabetes-A synthesis of international recommendations: Narrative review. Br. J. Sports Med. 2016, 50, 1379-1381. [CrossRef] [PubMed]

29. Wallace, T.M.; Levy, J.C.; Matthews, D.R. Use and abuse of HOMA modeling. Diabetes Care 2004, 27, 1487-1495. [CrossRef]

30. Ruffino, J.; Davies, N.; Morris, K.; Ludgate, M.; Zhang, L.; Webb, R.; Thomas, A.W. Moderate-intensity exercise alters markers of alternative activation in circulating monocytes in females: A putative role for PPAR $\gamma$. Eur. J. Appl. Physiol. 2016, 116, 1671-1682. [CrossRef]

31. Conti, F.F.; Brito, J.D.O.; Bernardes, N.; Dias, D.D.S.; Malfitano, C.; Morris, M.; Llesuy, S.F.; Irigoyen, M.-C.; De Angelis, K. Positive effect of combined exercise training in a model of metabolic syndrome and menopause: Autonomic, inflammatory, and oxidative stress evaluations. Am. J. Physiol. Regul. Integr. Comp. Physiol. 2015, 309, R1532-R1539. [CrossRef] [PubMed]

32. Dieli-Conwright, C.M.; Courneya, K.S.; Demark-Wahnefried, W.; Sami, N.; Lee, K.; Buchanan, T.A.; Spicer, D.V.; Tripathy, D.; Bernstein, L.; Mortimer, J. Effects of aerobic and resistance exercise on metabolic syndrome, sarcopenic obesity, and circulating biomarkers in overweight or obese survivors of breast cancer: A randomized controlled trial. J. Clin. Oncol. 2018, 36, 875-883. [CrossRef]

33. Ruhee, R.T.; Ma, S.; Suzuki, K. Protective effects of sulforaphane on exercise-induced organ damage via inducing antioxidant defense responses. Antioxidants 2020, 9, 136. [CrossRef]

34. López-Chillón, M.T.; Carazo-Díaz, C.; Prieto-Merino, D.; Zafrilla, P.; Moreno, D.A.; Villaño, D. Effects of long-term consumption of broccoli sprouts on inflammatory markers in overweight subjects. Clin. Nutr. 2019, 38, 745-752. [CrossRef]

35. Yu, C.; He, Q.; Zheng, J.; Li, L.Y.; Hou, Y.H.; Song, F.Z. Sulforaphane improves outcomes and slows cerebral ischemic/reperfusion injury via inhibition of NLRP3 inflammasome activation in rats. Int. Immunopharmacol. 2017, 45, 74-78. [CrossRef]

36. Magalhães, J.P.; Santos, D.A.; Correia, I.R.; Hetherington-Rauth, M.; Ribeiro, R.; Raposo, J.F.; Matos, A.; Bicho, M.D.; Sardinha, L.B. Impact of combined training with different exercise intensities on inflammatory and lipid markers in type 2 diabetes: A secondary analysis from a 1-year randomized controlled trial. Cardiovasc. Diabetol. 2020, 19, 1-11. [CrossRef] [PubMed]

37. Cuff, D.J.; Meneilly, G.S.; Martin, A.; Ignaszewski, A.; Tildesley, H.D.; Frohlich, J.J. Effective exercise modality to reduce insulin resistance in women with type 2 diabetes. Diabetes Care 2003, 26, 2977-2982. [CrossRef] [PubMed]

38. Zouhal, H.; Zare-Kookandeh, N.; Haghighi, M.M.; Daraei, A.; de Sousa, M.; Soltani, M.; Ben Abderrahman, A.; Tijani, J.M.; Hackney, A.C.; Laher, I.; et al. Physical activity and adipokine levels in individuals with type 2 diabetes: A literature review and practical applications. Rev. Endocr. Metab. Disord. 2021. [CrossRef] [PubMed]

39. Brooks, N.; Layne, J.E.; Gordon, P.L.; Roubenoff, R.; Nelson, M.E.; Castaneda-Sceppa, C. Strength training improves muscle quality and insulin sensitivity in Hispanic older adults with type 2 diabetes. Int. J. Med. Sci. 2007, 4, 19-27. [CrossRef]

40. Carey, A.; Febbraio, M. Interleukin-6 and insulin sensitivity: Friend or foe? Diabetologia 2004, 47, 1135-1142. [CrossRef]

41. Kubaszek, A.; Pihlajamäki, J.; Komarovski, V.; Lindi, V.; Lindström, J.; Eriksson, J.; Valle, T.T.; Hämäläinen, H.; Ilanne-Parikka, P.; Keinänen-Kiukaanniemi, S.; et al. Promoter polymorphisms of the TNF- $\alpha$ (G-308A) and IL-6 (C-174G) genes predict the conversion from impaired glucose tolerance to type 2 diabetes: The Finnish Diabetes Prevention Study. Diabetes 2003, 52, 1872-1876. [CrossRef] [PubMed]

42. Tsiotra, P.; Tsigos, C.; Raptis, S. TNF $\alpha$ and leptin inhibit basal and glucose-stimulated insulin secretion and gene transcription in the HIT-T15 pancreatic cells. Int. J. Obes. 2001, 25, 1018-1026. [CrossRef] [PubMed] 
43. Golbidi, S.; Laher, I. Exercise induced adipokine changes and the metabolic syndrome. J. Diabetes Res. 2014, $2014,726861$. [CrossRef] [PubMed]

44. Evans, J.L.; Goldfine, I.D.; Maddux, B.A.; Grodsky, G.M. Are oxidative stress-activated signaling pathways mediators of insulin resistance and $\beta$-cell dysfunction? Diabetes 2003, 52, 1-8. [CrossRef]

45. Wu, L.; Ashraf, M.H.N.; Facci, M.; Wang, R.; Paterson, P.G.; Ferrie, A.; Juurlink, B.H.J. Dietary approach to attenuate oxidative stress, hypertension, and inflammation in the cardiovascular system. Proc. Natl. Acad. Sci. USA 2004, 101, 7094-7099. [CrossRef]

46. Kursawe, R.; Eszlinger, M.; Narayan, D.; Liu, T.; Bazuine, M.; Cali, A.M.; D'Adamo, E.; Shaw, M.; Pierpont, B.; Shulman, G.I.; et al. Cellularity and adipogenic profile of the abdominal subcutaneous adipose tissue from obese adolescents: Association with insulin resistance and hepatic steatosis. Diabetes 2010, 59, 2288-2296. [CrossRef]

47. Armah, C.N.; Derdemezis, C.; Traka, M.H.; Dainty, J.R.; Doleman, J.F.; Saha, S.; Leung, W.; Potter, J.F.; Lovegrove, J.A.; Mithen, R.F.; et al. Diet rich in high glucoraphanin broccoli reduces plasma LDL cholesterol: Evidence from randomised controlled trials. Mol. Nutr. Food Res. 2015, 59, 918-926. [CrossRef]

48. Gordon, B.; Chen, S.; Durstine, J.L. The effects of exercise training on the traditional lipid profile and beyond. Curr. Sports Med. Rep. 2014, 13, 253-259. [CrossRef]

49. Saeidi, A.; Seifi-Ski-Shahr, F.; Soltani, M.; Daraei, A.; Shirvani, H.; Laher, I.; Hackney, A.C.; Johnson, K.E.; Basati, G.; Zouhal, H. Resistance training, gremlin 1 and macrophage migration inhibitory factor in obese men: A randomised trial. Arch. Physiol. Biochem. 2020, 28, 1-9. [CrossRef]

50. Varady, K.A.; Bhutani, S.; Klempel, M.C.; Kroeger, C.M. Comparison of effects of diet versus exercise weight loss regimens on LDL and HDL particle size in obese adults. Lipids Health Dis. 2011, 10, 1-5. [CrossRef] 